\title{
Reduced Use of Restricted and Danger-Labeled Pesticides in Florida Fresh Market Tomato Production (1992-2004)1
}

Mark A. Mossler ${ }^{2}$

- Restricted and "Danger"-labeled pesticides used in Florida fresh market tomato production include the insecticides endosulfan, esfenvalerate, methamidophos, methomyl, and permethrin, the herbicide paraquat, as well as the fumigants chloropicrin and methyl bromide. No fungicides used in Florida fresh market tomato production are classified as restricted use. These eight active ingredients account for over $95 \%$ of the restricted or exclusively labeled "Danger" pesticides employed in Florida fresh market tomato production (1-7).

- Pesticide use values for 2004 compared to peak usage data for the period 1992 through 2004 demonstrate a $75 \%$ reduction in the application of restricted or "Danger"-labeled insecticides in fresh market tomato. Paraquat use was reduced by $31 \%$. Fumigant use (17\% reduction) was mainly influenced by rate reduction, rather than reduction of use (1-7).
- The reduction in use of the restricted use and "Danger"-labeled pesticides is believed to be due to strong adoption of integrated pest management (IPM) principles by Florida tomato growers, working in conjunction with Extension agents and professionals.

- Increased IPM adoption and reduced spraying of these ingredients is reflected in a $67 \%$ decrease in methamidophos residues (from 0.021 PPM to 0.007 PPM) in Florida fresh market tomato from the period 1997 to 2003 (8). These values are far below the tolerance in tomato for methamidophos (1.0 PPM).

The General Accounting Office (GAO) audit of the U.S. Department of Agricultures (USDA) IPM program during 2000-2001 was conducted to determine whether USDA appropriately met the stated goal of the 1994 IPM Initiative, which was to foster adoption of IPM practices on $75 \%$ of U.S. planted crop land by the year 2000 (9). Indeed, from 1994 through 2000, adoption of IPM practices

\footnotetext{
1. This document is PI-87, one of a series of publications of the Pesticide Information Office, Agronomy Department, Florida Cooperative Extension Service, Institute of Food and Agricultural Sciences, University of Florida. For additional Information, contact the Pesticide Information Office, University of Florida, P. O. Box 110710, Gainesville, Fl 32611-0710, (352) 392-4721. Published November 2005. Please visit the EDIS Web site at http://edis.ifas.ufl.edu.

2. Mark A. Mossler, Doctor of Plant Medicine, Pesticide Information Office, Agronomy Department. Florida Cooperative Extension Service, Institute of Food and Agricultural Sciences, University of Florida, Gainesville, FL 32611-0710.
}

The Institute of Food and Agricultural Sciences (IFAS) is an Equal Opportunity Institution authorized to provide research, educational information and other services only to individuals and institutions that function with non-discrimination with respect to race, creed, color, religion, age, disability, sex, sexual orientation, marital status, national origin, political opinions or affiliations. U.S. Department of Agriculture, Cooperative Extension Service, University of Florida, IFAS, Florida A. \& M. University Cooperative Extension Program, and Boards of County Commissioners Cooperating. Larry Arrington, Dean 
increased from around $40 \%$ to nearly $70 \%$, yet pesticide use (in terms of weight per unit of area) increased slightly. The GAO concluded that USDA's IPM program had not yet developed the methods for measuring IPM's environmental and economic results, among other things.

Contrary to the GAO findings, this analysis will demonstrate that Florida fresh market tomato growers are committed to IPM principles and practices. Lack of adherence to these principles often leads to resistance, which in turn leads to crop loss or failure. The USDA has collected and published pesticide use data on select Florida crops every other year from 1992 through 2004. Fresh market tomatoes have been enumerated each of these years, for a total of seven data sets. Data for all eight active ingredients examined in this analysis are available for even-numbered years. The total pounds of each active ingredient used in Florida fresh market tomato were divided by the amount of Florida tomato acreage (between 40,000 and 50,000 acres) each year. The values from 2004 were compared to peak years of use.

From Table 1, it is apparent that use reductions of between 74 and 79\% (in comparison to the peak year of 1994) have occurred since 1998, with the last year of data (2004) reflecting a 75\% reduction in restricted or "Danger"-labeled insecticide use in Florida tomato production.

A similar but less dramatic reduction has occurred in fumigant use in Florida fresh market tomato production (Table 2). In this case, the impetus for reduction in use has come mainly from the methyl bromide phaseout that is occurring under the Montreal Protocol on Substances that Deplete the Ozone Layer. This trend is mainly due to the reduction in rate, rather than a reduction in use (i.e., all fresh market tomato acreage is fumigated).

Use reductions of between 17 and $26 \%$ (in comparison to the peak year of 2000) have occurred since 2002. The use of methyl bromide will continue to decline, until it is completely phased out as an agricultural pesticide. However, its use may well be supplanted by methyl iodide or other fumigants, which would likely carry the restricted use status and "Danger" labeling.
Use of the only restricted herbicide (paraquat) in Florida-grown fresh market tomatoes has also decreased from the historic highs (Table 3). In this case, use reduction is cost and IPM related. Glyphosate pricing was easing (and use increasing) during the decade of the 90 's, and paraquat-resistant weeds (such as American black nightshade and goosegrass) were noted in several areas of the state.

Use reductions of paraquat between 31 and $87 \%$ (in comparison to the peak year of 1992) have occurred since 1998 in Florida fresh market tomato production.

This reduction in use of restricted and "Danger"-labeled pesticides decreases potential hazards for mixer/loader and application personnel, as well as harvest crews. It also reduces potential hazards for associated wildlife and watersheds. Unfortunately, data that would document these trends do not exist. However, data are available for pesticide residues in vegetables, including fresh market tomato. The USDA's Pesticide Data Program has reported residues of pesticides in fresh market tomato yearly from 1996. Reduced spraying of restricted pesticides is reflected in a $67 \%$ decrease in methamidophos residues (from 0.021 PPM to 0.007 PPM) in Florida fresh market tomato from the period 1997 to 2003 (8). These values are far below the 1.0 PPM tolerance in tomato for methamidophos, demonstrating proper use of the insecticide when employed for pest control.

Another manner to measure IPM adoption is use of "reduced risk" pesticides, which are generally more selective than restricted or "Danger"-labeled pesticides. Insecticides such as spinosad and imidacloprid have been adopted by Florida fresh market tomato growers as early as the mid to late 90's, and 2004 data have revealed use of other such materials including indoxacarb, pymetrozine, and pyriproxyfen. None of these insecticides are restricted or "Danger"-labeled when purchased individually in Florida. It is important to note that these "reduced risk" products are always more expensive than older, off-patent materials. Extension agents and professionals have been essential in educating Florida tomato growers, so that costs using "reduced risk" materials are commensurate with previous costs. 


\section{References}

1. U.S. Dept. of Agriculture/National Agricultural Statistics Service. (2005). Agricultural Chemical Usage, Vegetables, 2004 Summary. Agricultural Statistics Board, National Agricultural Statistics Service, U.S. Department of Agriculture.

2. U.S. Dept. of Agriculture/National Agricultural Statistics Service. (2003). Agricultural Chemical Usage, Vegetables, 2002 Summary. Agricultural Statistics Board, National Agricultural Statistics Service, U.S. Department of Agriculture.

3. U.S. Dept. of Agriculture/National Agricultural Statistics Service. (2001). Agricultural Chemical Usage, Vegetables, 2000 Summary. Agricultural Statistics Board, National Agricultural Statistics Service, U.S. Department of Agriculture.

4. U.S. Dept. of Agriculture/National Agricultural Statistics Service. (1999). Agricultural Chemical Usage, Vegetables, 1998 Summary. Agricultural Statistics Board, National Agricultural Statistics Service, U.S. Department of Agriculture.

5. U.S. Dept. of Agriculture/National Agricultural Statistics Service. (1997). Agricultural Chemical Usage, Vegetable Crop Summary 1996. Agricultural Statistics Board, National Agricultural Statistics Service, U.S. Department of Agriculture.

6. U.S. Dept. of Agriculture/National Agricultural Statistics Service. (1995). Agricultural Chemical Usage, Vegetable Crop Summary 1994. Agricultural Statistics Board, National Agricultural Statistics Service, U.S. Department of Agriculture.

7. U.S. Dept. of Agriculture/National Agricultural Statistics Service. (1993). Agricultural Chemical Usage 1992 Vegetables Summary. Economic Research Service, Washington, D.C.
8. U.S. Dept. of Agriculture/Agricultural Marketing Service. Florida specific fresh market tomato analyses obtained from USDA's Pesticide Data Program.

9. Agricultural Pesticides - Management Improvements Needed to Further Promote Integrated Pest Management. GAO-01-815. August 2001. U.S. General Accounting Office, Washington, D.C. 
Reduced Use of Restricted and Danger-Labeled Pesticides in Florida Fresh Market Tomato....

Table 1. Total Insecticide Use in Florida Tomato Production

\begin{tabular}{||c|c|c|c||}
\hline \hline Year & Total Insecticide Use (Pounds) & Tomato Acreage & Pounds/Acre \\
\hline 1992 & 227,300 & 49,400 & 4.6 \\
\hline 1994 & 385,100 & 47,900 & 8.0 \\
\hline 1996 & 129,100 & 40,000 & 3.2 \\
\hline 1998 & 85,400 & 40,600 & 2.1 \\
\hline 2000 & 69,800 & 42,000 & 1.7 \\
\hline 2002 & 77,400 & 45,000 & 1.7 \\
\hline 2004 & 84,400 & 42.400 & 2.0 \\
\hline \multicolumn{2}{|l|}{ *Pounds of endosulfan, esfenvalerate, methamidophos, methomyl, and permethrin combined. } \\
\hline
\end{tabular}

Table 2. Fumigant Use in Florida Tomato Production

\begin{tabular}{||c|c|c|c||}
\hline \hline Year & Total Fumigant Use (Pounds) ${ }^{*}$ & Tomato Acreage & Pounds/Acre \\
\hline 1992 & $9,053,400$ & 49,400 & 183 \\
\hline 1994 & $10,109,500$ & 47,900 & 211 \\
\hline 1996 & $7,187,800$ & 40,000 & 180 \\
\hline 1998 & $6,844,300$ & 40,600 & 169 \\
\hline 2000 & $8,922,900$ & 42,000 & 212 \\
\hline 2002 & $7,077,100$ & 45,000 & 157 \\
\hline 2004 & $7,518,300$ & 42,400 & 177 \\
\hline *Pounds of methyl bromide and chloropicrin combined. \\
\hline
\end{tabular}

Table 3. Use of the only Restricted Herbicide (Paraquat) in Florida-grown Tomato

\begin{tabular}{||c|c|c|c||}
\hline \hline Year & Total Paraquat Use (Pounds) & Tomato Acreage & Pounds/Acre \\
\hline 1992 & 33,000 & 49,400 & 0.67 \\
\hline 1994 & 20,600 & 47,900 & 0.43 \\
\hline 1996 & 22,900 & 40,000 & 0.57 \\
\hline 1998 & 12,600 & 40,600 & 0.31 \\
\hline 2000 & 10,000 & 42,000 & 0.24 \\
\hline 2002 & 4,200 & 45,000 & 0.09 \\
\hline 2004 & 19,400 & 42,400 & 0.46 \\
\hline \hline
\end{tabular}

